\title{
0536 MANAGING AND PROMOTING CHILD SAFETY IN THE CITY NEW HOLISTIC MODEL
}

K Shira, K Dafna, K Michal, B S Gali, B Zvi, H L Michal, 0 Silbinger* Correspondence: Beterem - Safe Kids, 18 Hasivim Street, P.O.B. 7050 Petach-Tikva 49170, Israel

\subsection{6/ip.2010.029215.536}

Introduction Unintentional injuries are a major cause of child mortality and morbidity in Israel. Municipal authorities promote child safety via different activities and departments; however child safety is not recognised as a single integrated issue in need of comprehensive management.

Objective To develop an holistic model for Safe Cities, combining methods of organisation counselling, risk management and health promotion. Concept 'Safe Cities for Children' is based on the safe community model, with the addition of supplementary domains including: the City as an Organisation. Using tools of organisation counselling to incorporate a safety culture in the municipality. Functional Responsibility. Recognition of and obligation to the municipality's functional responsibility to see to child safety. Safety Management and Promotion. Commitment to comprehensive child safety management, as well as engage in promotion of child safety via activities. Standards and tools (1) Safe City Guideline developed based on OHSAS 18001, Safe Community model and international labour organisation (ILO) documentation. (2) Initial risk survey and mapping of the state of child safety 


\section{IP Safety 2010 abstracts}

in the municipality as a baseline prior to launching the program. (3) Minimal Data Set (MDS) a uniform MDS on child injuries adapted for municipalities. (4) Organisation counselling model - developed for counselling municipalities in the field of child safety.

Validation Twenty municipal authorities in Israel have joined the Safe Cities program since 2001; half are in the low socio-economic bracket including Arab and Jewish Ultra Orthodox population. Results of initial evaluation of the model will be presented. 